\title{
Pierre Gy Tribute
}

\author{
Ana Carolina Chieregati
}

was fortunate to meet Dr Pierre Gy shortly after WCSB7 in Bordeaux. As I was sadly not able to accompany the group that visited Pierre on the last day of the conference, I arranged to meet him alone on my way to the airport going home to Brazil.

This I will never regret-or forget. Behind the genius of the Theory of Sampling, I found a sincerely humble, kind and thoroughly warm-hearted man, as is in every way documented by the few photographs that I was able to have taken. Better than any words, they show an instant rapport between the disciple and the master, the man I will always remember and cherish. I am so thankful to all my friends who made that moment possible, allowing me to experience those few priceless minutes that filled my soul with joy. I was truly honoured to meet Pierre Gy.

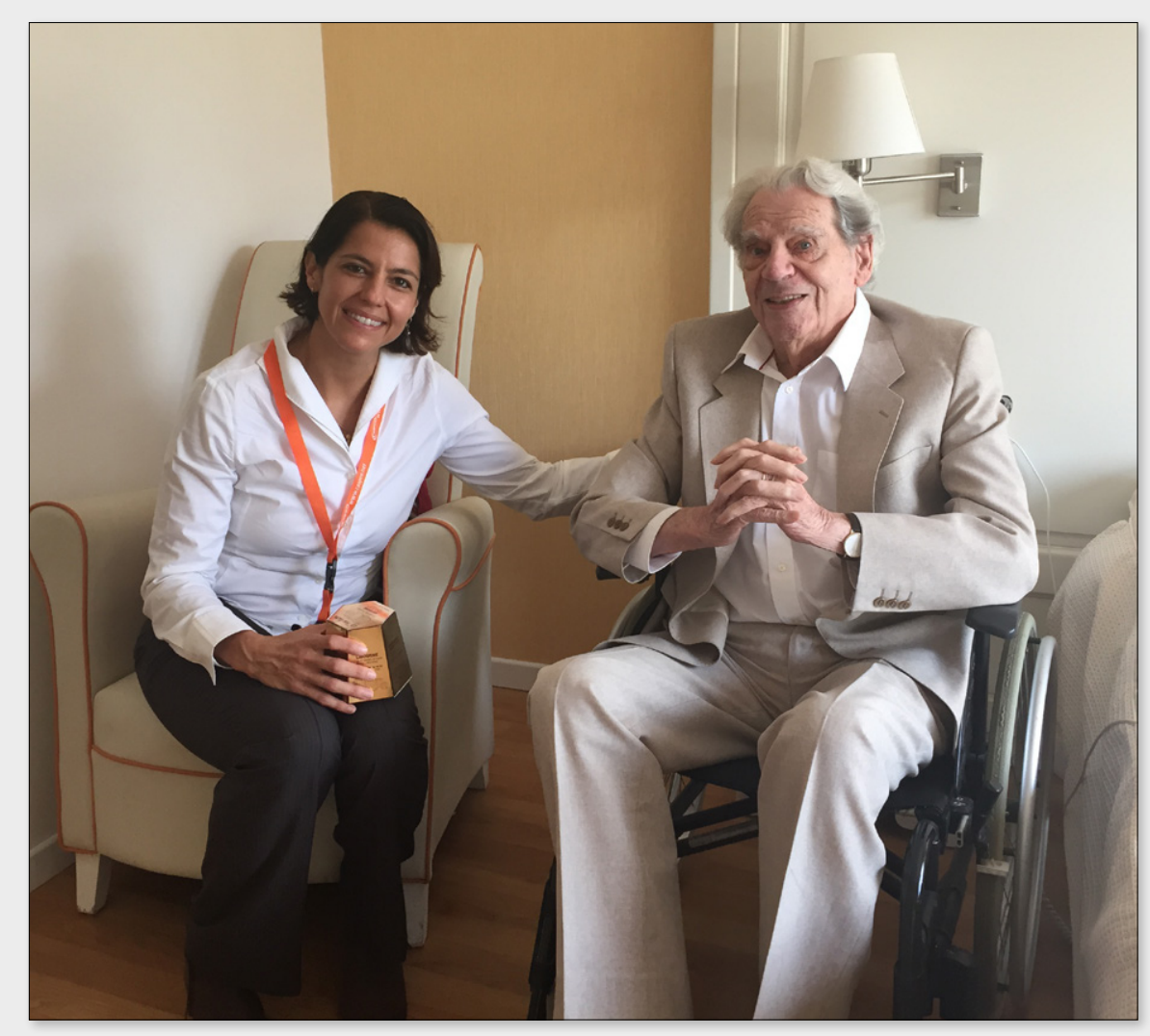

Ana Carolina Chieregati with Pierre Gy in Bordeaux. 